\title{
Quantitative Understanding of the Environmental Effect on B10 Copper Alloy Corrosion in Seawater
}

\author{
Yikun Cai ${ }^{1}$, Yuanming Xu ${ }^{1,2}$, Yu Zhao ${ }^{3}$, Weifang Zhang ${ }^{3}{ }^{\circledR}$, Jinghua Yao ${ }^{4}$, Mumeng Wei ${ }^{4}$, Kun Zhou ${ }^{5}$ \\ and Xiaobing $\mathrm{Ma}^{3, *}$ \\ 1 School of Aeronautic Science and Engineering, Beihang University, Beijing 100191, China; \\ by1314120@buaa.edu.cn (Y.C.); xuymg@sina.com (Y.X.) \\ 2 Beijing Advanced Discipline Center for Unmanned Aircraft System, Beijing 100191, China \\ 3 School of Reliability and Systems Engineering, Beihang University, Beijing 100191, China; \\ zhaoyu@buaa.edu.cn (Y.Z.); 08590@buaa.edu.cn (W.Z.) \\ 4 State Key Laboratory for Marine Corrosion and Protection, Xiamen 361000, China; yaolele725@163.com (J.Y.); \\ syamm2011@163.com (M.W.) \\ 5 Southwest Institute of Technology and Engineering, Chongqing 400039, China; zkdudu@163.com \\ * Correspondence: maxiaobing@buaa.edu.cn; Tel.: +86-010-82316074
}

check for updates

Citation: Cai, Y.; Xu, Y.; Zhao, Y.; Zhang, W.; Yao, J.; Wei, M.; Zhou, K.; $\mathrm{Ma}, \mathrm{X}$. Quantitative Understanding of the Environmental Effect on B10 Copper Alloy Corrosion in Seawater. Metals 2021, 11, 1080. https:// doi.org/10.3390/met11071080

Academic Editor: Petros E. Tsakiridis

Received: 3 June 2021

Accepted: 1 July 2021

Published: 6 July 2021

Publisher's Note: MDPI stays neutral with regard to jurisdictional claims in published maps and institutional affiliations.

Copyright: (c) 2021 by the authors. Licensee MDPI, Basel, Switzerland. This article is an open access article distributed under the terms and conditions of the Creative Commons Attribution (CC BY) license (https:// creativecommons.org/licenses/by/ $4.0 /)$.

\begin{abstract}
Corrosion in natural seawater is difficult to simulate in a laboratory due to the slow rate and complexity of the corrosion process which involves multiple influential factors. This paper aims to explore the quantitative effect of environmental factors on corrosion process and find the best experimental conditions which represent the actual environment and have the best acceleration effect. A new framework is followed in this paper which consists of three parts: design of experiments, outdoor and laboratory corrosion tests, and corrosion mechanism consistency confirmation. A $\mathrm{L}_{6}\left(3^{1} \times 2^{2}\right)$ orthogonal experiment is designed in laboratory to study the effect of temperature, salinity, and dissolved oxygen on marine corrosion behavior of B10 copper alloy. In each test, $\mathrm{H}_{2} \mathrm{O}_{2}$ is added in seawater to accelerate the corrosion process. Outdoor exposure tests are also conducted in natural seawater. Results show that the corrosion process in laboratory and outdoor follows the same mechanism, in view of corrosion product and morphology, corrosion kinetics, as well as mechanical properties. With the help of quantitative analysis of the test results, a better acceleration condition can be designed.
\end{abstract}

Keywords: marine corrosion; quantitative design; accelerated corrosion test; mechanism consistency

\section{Introduction}

Corrosion of metals in seawater is a complex process involving multiple factors, which include dissolved oxygen, temperature, salinity, $\mathrm{pH}[1,2]$, as well as biological activities $[3,4]$. There have been many researches aiming to distinguish important influential factors and their effects on the corrosion process.

The effect of each environmental factor may act in different ways when they are considered individually or together. A simple example is that increase of temperature can lead to the increase of diffusion rate and accelerate the corrosion process. However, in the open sea environment, the corrosion rate is observed to first increase with temperature and then decrease due to the escape of oxygen from seawater [5]. Salinity has a similar effect on corrosion rate and its effect on oxygen solubility is even greater [2,5]. When more factors are considered, the potential net effects are much more complicated [6,7]. For example, the individual effect of $\mathrm{pH}$, temperature, and salinity on corrosion rate can be canceled out, improved, or moderated as a result of the combined effect with another factor [7].

To obtain the degradation trend of material properties, numerous experiments both in outdoor and laboratory environments are conducted. Outdoor exposure experiments are usually carried out in natural seawater and are thought the most representative of 
the actual conditions. The long-term corrosion kinetics in seawater is rather complicated due to the difference of controlling factors at different phases. Melcher [8] developed a four-phase model to predict corrosion loss in the marine environment [9]. However, outdoor experiments usually take years [10] or even decades [9,11,12], which makes it impossible to collect the data within a short period. In addition, the results are difficult to be extrapolated to environments different from where the experiments are conducted.

Some researchers also simulate the corrosion process in the laboratory by immersing the specimens in artificial seawater. Corrosion behavior and reaction rate can be changed by controlling the influential factors in a proper way. Cai et al. [13] studied the galvanic corrosion behaviors of carbon fiber composite coupled to aluminum in artificial seawater and found the change of grinding condition, the concentration of artificial seawater, applied torque, and applied current will result in changes in corrosion rate. Zhang et al. [14] found tribo-corrosion behavior of 304 stainless steel is different when halide ions concentration in seawater is changed. A well-designed experiment is helpful to study the effect of each factor, distinguish important factors, as well as find the acceleration factor [13].

However, differences exist between artificial seawater (ASW) and natural seawater (NSW). For example, Santos et al. [15] studied the corrosion of brass in both natural and artificial seawater (prepared by dissolving sea salts into deionized water). They found that the corrosion rate of brass in NSW is much higher than in ASW. Different alloys may also exhibit different resistance to tribo-corrosion in artificial seawater and distilled water [16]. The reason lies in the difference of organic matter [15] and microorganisms $[15,17]$ between NSW and ASW.

Copper-nickel alloys have been widely used in various industrial activities, such as condenser tubes, heat exchangers, and piping systems owing to its outstanding resistance to corrosion, especially in seawater. Researchers have conducted corrosion experiments on this alloy to study its corrosion behavior under various environmental conditions, such as different flow velocity [18], temperature [19], $\mathrm{pH}$ [20], dissolved oxygen [21], chloride concentration [20], and many other factors [18]. Most of these studies used ASW (mainly $3.5 \% \mathrm{NaCl}$ solution) [20,22], which differs from NSW.

The limitations of these laboratory experiments exist in three ways. Firstly, only short-term corrosion behavior can be observed as no significant accelerating effect is involved to shorten the total test time. In some researches, the test time needed to reach the same corrosion amount is still too long [23], and some are even longer than outdoor conditions [15]. Secondly, it is difficult to extrapolate the results to outdoor experiments because no equations are obtained to quantitatively describe how each environmental factor influences the corrosion process. Thirdly, no explicit clues are traced to guarantee that the corrosion process follows the same mechanism as in outdoor environments. The corrosion product and surface morphology may be different between NSW and ASW [23], indicating different corrosion processes.

In view of this, it is important to combine outdoor exposure and laboratory accelerated corrosion tests. To achieve this, a new framework is needed, which includes three parts: design of experiments, outdoor and laboratory corrosion tests, corrosion mechanism consistency confirmation. In this paper, both outdoor exposure and laboratory accelerated corrosion tests of B10 copper alloys are conducted to investigate the mechanism of the corrosion process and degradation trend of properties. Multiple accelerated corrosion experiments are designed in a more quantitative way to study the effects of temperature, salinity, and dissolved oxygen on corrosion and find out the best conditions for accelerated tests. Both corrosion loss and mechanical properties of the experimental specimens are measured. The elements of corrosion products and the cleaned surface are analyzed to guarantee that outdoor and laboratory tests follow the same mechanism. 


\section{Experiments}

\subsection{Outdoor Exposure Corrosion Test}

The size of test specimens for field exposure is $200 \times 100 \times 3 \mathrm{~mm}^{3}$. The outdoor exposure experiments are carried out at Xiamen, Fujian province of China. The annual average temperature is around $22{ }^{\circ} \mathrm{C}$. The monthly average temperature reaches the minimal value of $15{ }^{\circ} \mathrm{C}$ in winter and reaches the maximal value of $28-32{ }^{\circ} \mathrm{C}$ in summer. The annual average salinity is about $3.0 \%$, varying in the range of $2.8-3.2 \%$. The annual average dissolved oxygen varies between 7.3 and $7.7 \mathrm{mg} / \mathrm{L}$, while the distribution range is $6.0-8.8 \mathrm{mg} / \mathrm{L}$ all around the year.

The metal weight loss, tensile strength, yield strength, and bending strength of specimens are measured after $0.5,1,1.5,2$, and 3 years following standard procedures (ISO 9226-2012 for weight loss, GB/T 228.1-2010 for tensile strength and yield strength, and GB/T 232-2010 for bending strength). The mechanical test equipment is the AG-X type universal testing machine of SHIMADZU company. Three specimens are measured each time and they will not be returned to the immersion condition anymore. Thus, a total number of $15(5 \times 3)$ specimens are immersed in seawater at the beginning of the test. The Surface morphology is observed by scanning electron microscopy (SEM; ULTRA55 of ZEISS, Oberkochen, Germany) and corrosion product is analyzed by energy-dispersive X-ray spectroscopy (EDS; X-MAX50 of Oxford Instruments, Oxford, UK) for both laboratory and field test specimens. The chemical composition of the B10 copper alloys is given in Table 1.

Table 1. Chemical composition (wt\%) of B10 copper alloy.

\begin{tabular}{cccccccc}
\hline $\mathbf{S i}$ & $\mathbf{P}$ & $\mathbf{F e}$ & $\mathbf{S}$ & $\mathbf{Z n}$ & $\mathbf{N i}$ & $\mathbf{M n}$ & $\mathbf{C u}$ \\
\hline$<0.15$ & $<0.02$ & 1.20 & 0.0013 & $<0.3$ & 9.76 & 0.74 & Remainder \\
\hline
\end{tabular}

Corrosion rate $C R(\mu \mathrm{m} / \mathrm{a})$ is calculated with $C R=\frac{M_{0}-M_{t}}{2 \cdot \rho \cdot\left(L_{0} \cdot L_{b}\right) \cdot t^{\prime}}$, in which $M_{0}$ is the weight before the test begins, $M_{t}$ is the weight of $t$ years test after corrosion products removal, $\rho$ is the density of B10 copper alloy $\left(8.96 \mathrm{~g} . \mathrm{cm}^{-3}\right), L_{\mathrm{a}}$ and $L_{\mathrm{b}}$ are the length and width of the specimen, respectively.

\subsection{Laboratory Accelerated Corrosion Test}

For the measurement of the corrosion loss, the size of the test specimens for the laboratory accelerated tests is $100 \times 50 \times 3 \mathrm{~mm}^{3}$. For the measurement of the mechanical properties, the size of the test specimens is $200 \times 100 \times 3 \mathrm{~mm}^{3}$. Three parallel specimens were used at each time. Before the experiments start, all the specimens were measured for length, width, and thickness, washed with anhydrous ethanol, dried for $24 \mathrm{~h}$, and weighed.

Six accelerated corrosion tests are carried out in the laboratory under different conditions. The orthogonal design method is employed and an $\mathrm{L} 6\left(3^{1} \times 2^{2}\right)$ table is used as given in Table 2 (G1-G6). The temperature is controlled at $25^{\circ} \mathrm{C}, 45^{\circ} \mathrm{C}$, and $60^{\circ} \mathrm{C}$ using a constant temperature water bath. The salinity of the corrosion solution is controlled at $3.0 \%$ and $3.5 \%$ by adding $\mathrm{NaCl}$ solutions into natural seawater. Dissolved oxygen is marked as saturated when air is blown into the water and unsaturated when no air is blown into the water. In each test, $0.05 \mathrm{~mol} / \mathrm{L} \mathrm{H}_{2} \mathrm{O}_{2}$ is added as the depolarizer to accelerate the corrosion process. Three specimens are measured for corrosion loss and mechanical properties each time (after 1, 2, 4, 6, 8, 16, and 32 weeks of the test) and the average values are calculated. The test solution is replaced every three days. EDS and SEM are also used to analyze the content and morphology of the corrosion product. 
Table 2. The conditions of accelerated corrosion tests.

\begin{tabular}{ccccc}
\hline No. & Temperature $\left({ }^{\circ} \mathbf{C}\right)$ & Salinity $\mathbf{( \% )}$ & $\mathbf{H}_{\mathbf{2}} \mathbf{O}_{\mathbf{2}} \mathbf{( \mathbf { m o l } / \mathbf { L } )}$ & Dissolved Oxygen \\
\hline G0 & 25 & 3.0 & 0 & Unsaturated \\
G1 & 25 & 3.0 & 0.05 & Unsaturated \\
G2 & 25 & 3.5 & 0.05 & Saturated \\
G3 & 45 & 3.0 & 0.05 & Saturated \\
Gr & 45 & 3.0 & 0.05 & Unsaturated \\
G4 & 45 & 3.5 & 0.05 & Unsaturated \\
G5 & 60 & 3.0 & 0.05 & Unsaturated \\
G6 & 60 & 3.5 & 0.05 & Saturated \\
\hline
\end{tabular}

In order to examine the acceleration effect of $\mathrm{H}_{2} \mathrm{O}_{2}$ and the corrosion mechanism with and without $\mathrm{H}_{2} \mathrm{O}_{2}$, an extra test is conducted which is denoted as G0. Another experiment $\mathrm{Gr}$ is also conducted to be referred to when discussing the influence of each environmental factor which is demonstrated in detail in Section 3.3.2. Polarization curve is also measured by electrochemical workstation (Autolab PGSTAT302N of Metrohm, Switzerland) for G0 and G1 to verify the acceleration effect of $\mathrm{H}_{2} \mathrm{O}_{2}$. The potential range is $\pm 0.1 \mathrm{~V}$ around the OCP (open circuit potential) and the scan rate is $0.001 \mathrm{~V} / \mathrm{s}$.

\section{Results and Discussion}

\subsection{Outdoor Test Result}

\subsubsection{Corrosion Process}

In the field exposure tests, after 0.5 years for the specimens immersed in seawater, more than $95 \%$ of the specimen surface is covered by dense corrosion products. The surface is all covered by corrosion products after 1 year and becomes thicker along with time. The morphology of the surface after corrosion products are removed indicated that the corrosion process is not uniform on the surface. After 0.5 years of exposure, the specimen surface is slightly uneven due to the initiation of tiny pits. With the proceeding of the corrosion process, the uneven area expands and small pits grow and become bigger and deeper. After 1.5 years, the specimen surface has turned to undulating peaks and valleys as shown in Figure 1.

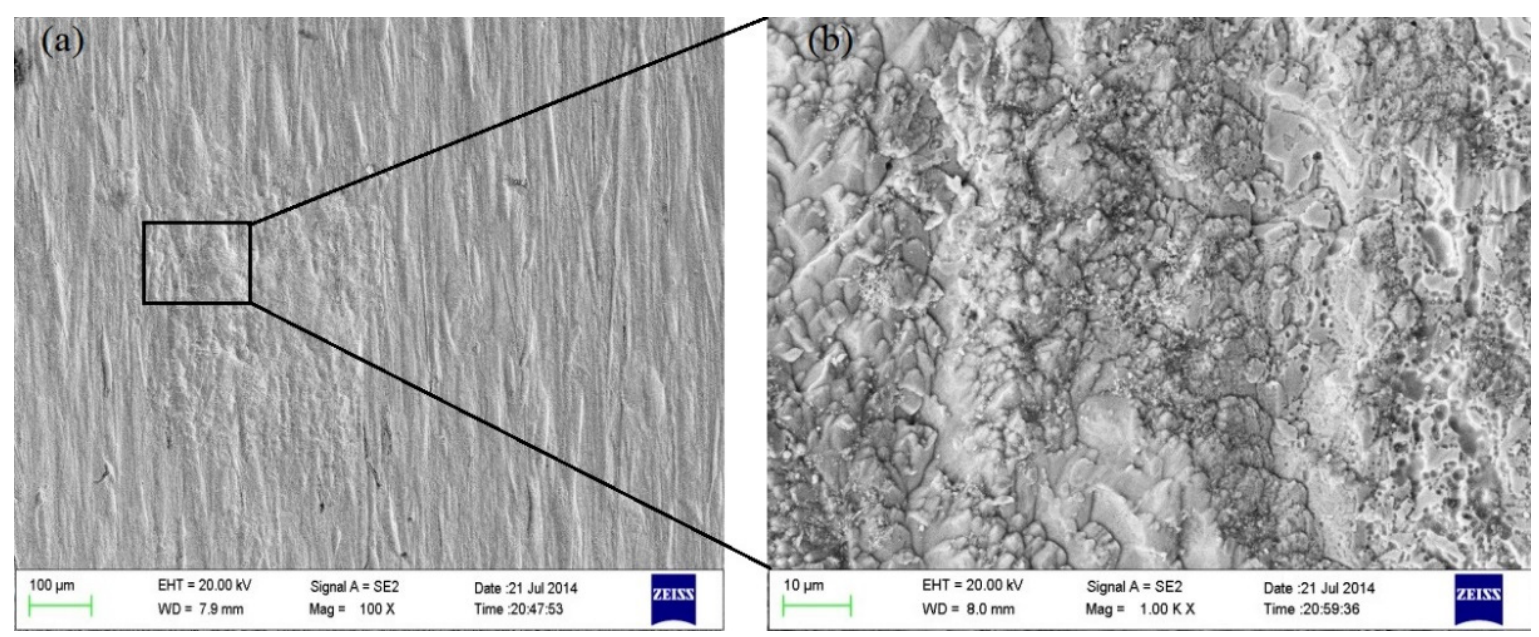

Figure 1. The surface morphology by SEM after 1.5 years exposure: (a) $100 \times$; (b) $1000 \times$.

During the exposure, B10 copper alloy exhibits good resistance to the attachment of sea creatures. No obvious attachment is found on the 0.5 year specimen surface and the attached area is only a small portion of the surface (less than $20 \%$ ) even after 3 years of exposure. This is because the corrosion products $\left(\right.$ mainly $\mathrm{Cu}_{2} \mathrm{O}$ ) are poison to sea creatures [24]. The formation of $\mathrm{Cu}_{2} \mathrm{O}$ is made up of the following steps: 
(i) $\mathrm{Cu}$ ion loses an electron and forms $\mathrm{Cu}^{+}$, which is $\mathrm{Cu} \rightarrow \mathrm{Cu}^{+}+\mathrm{e}$;

(ii) $\mathrm{Cu}^{+}$reaches the metal surface and reacts with $\mathrm{Cl}^{-}$in seawater, which is $\mathrm{Cu}^{+}+\mathrm{Cl}^{-} \rightarrow \mathrm{CuCl}$;

(iii) With the increase of $\mathrm{CuCl}$ and decrease of $\mathrm{Cl}^{-}, \mathrm{CuCl}$ tends to hydrolyze, which is $2 \mathrm{CuCl}+\mathrm{H}_{2} \mathrm{O} \rightarrow \mathrm{Cu}_{2} \mathrm{O}+2 \mathrm{HCl}$. $\mathrm{Cu}_{2} \mathrm{O}$ is more stable thermodynamically and adheres to the surface.

\subsubsection{Mass and Mechanical Property Loss}

Figure 2 shows the relationship between corrosion loss/rate of B10 copper alloy and corrosion time. It is seen that while corrosion loss increases with time, the corrosion rate slows down gradually. Both corrosion loss and corrosion rate can be well fitted with equation $y=a . t^{-b}$ and the correlation coefficients $R^{2}$ is greater than 0.9 . If we assume that the corrosion process reaches a stable state when the change of corrosion rate is less than $10 \%$, as suggested by Morcillo [25] for atmospheric corrosion, it is determined that the corrosion process reaches the stable state after 4.9 years according to the fitting equation [26]. This is because the specimen surface is covered with dense corrosion products (shown in Figure 3), which hinder the adsorption and transportation of oxygen and corrosive ions.

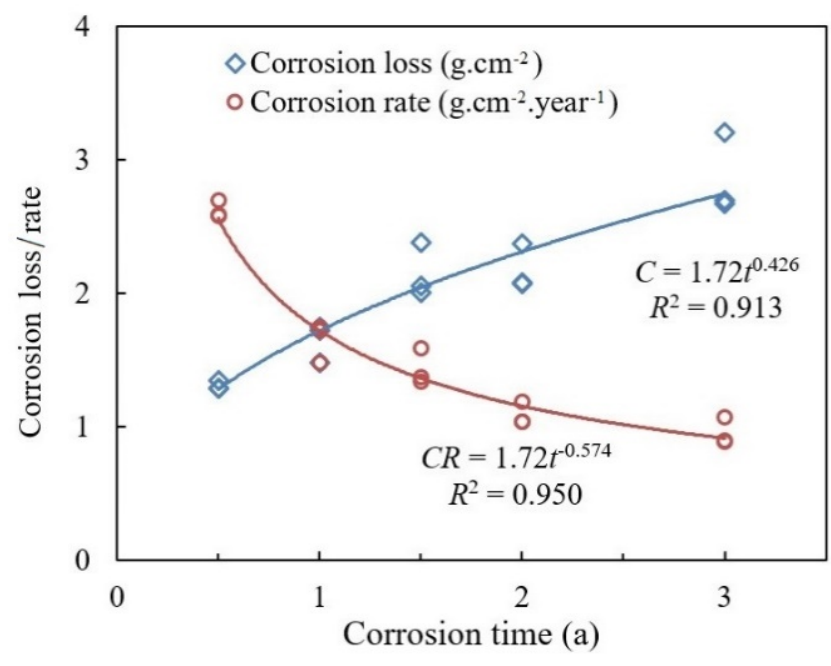

Figure 2. The relationship between corrosion loss/rate and corrosion time.
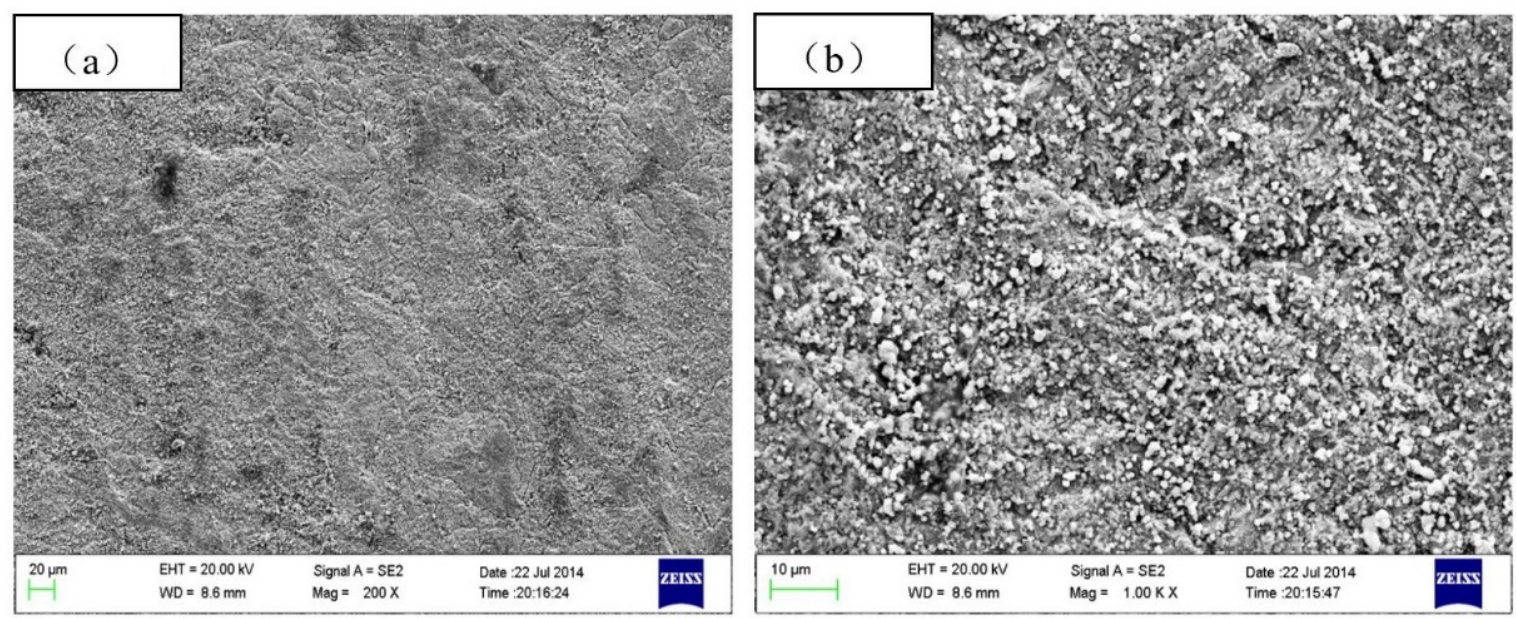

Figure 3. The SEM morphology of corrosion products after 1.5 years exposure: (a) $200 \times$; (b) $1000 \times$.

Figure 4 shows the relationship between pit depth and corrosion time and the pit morphologies after 2 years. No corrosion pits with a depth greater than $0.05 \mathrm{~mm}$ are detected 
on specimens exposed for 0.5 years. After 1 year, more and more pits initiate and grow on the surface, and the average pit depth shows approximately a linear growth trend with corrosion time. The pit's depth has bigger and bigger difference as the corrosion process proceeds. The metal surface mainly suffers uniform corrosion with random distributed localized corrosion pits in some areas. Figure $4 \mathrm{~b}$ shows the morphology of the corroded surface after 2 years. Three areas can be found in this figure: a big and deep pit (in the blue circle), areas containing many small pits (in the red circle), and flat surface areas (the rest parts). The maximum pit depth has a sharp increase after 2 years (mainly due to the appearance of deep pits), but it does not exceed $0.3 \mathrm{~mm}$. It can be seen that B10 copper alloy has good corrosion resistance in the natural marine environment. Affected by the dense product film on the surface, the corrosion reaction is mainly pitting corrosion which develops in depth. Once corrosion pits appear on the metal surface, they will grow rapidly in the following $1-1.5$ years.

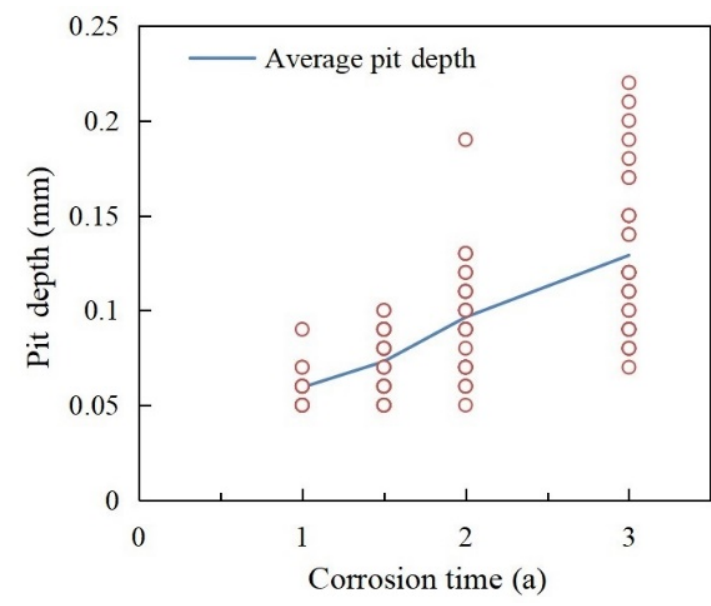

(a)

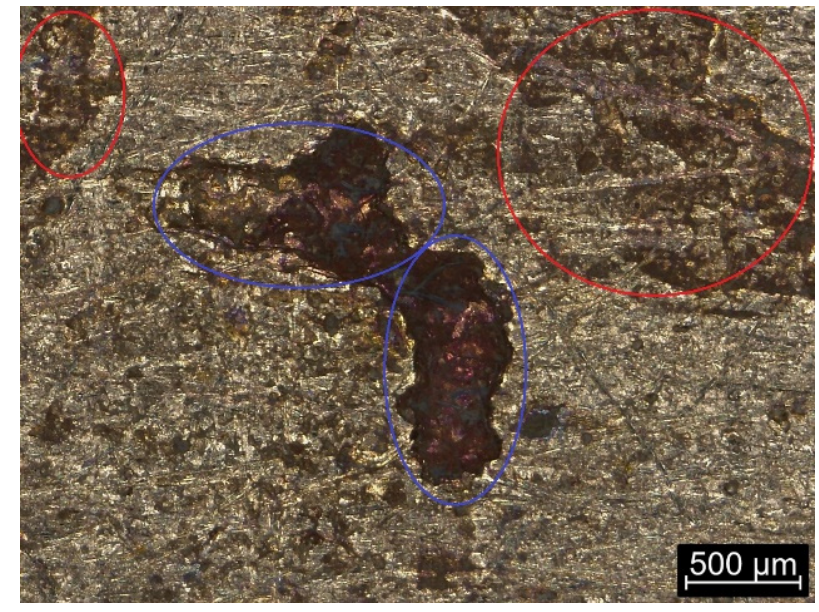

(b)

Figure 4. (a) The relationship between pit depth and corrosion time, (b) pit morphologies after 2 years.

Figure 5 shows the change of mechanical properties over time. It is seen that the tensile properties and three-point bending properties deteriorate after they are exposed in seawater. Before the exposure, the average values of tensile strength, yield strength, and three-point bending strength of the specimens are $314.7 \mathrm{MPa}, 143.2 \mathrm{MPa}$, and $764.3 \mathrm{MPa}$, respectively. After 3 years of exposure, the average loss of tensile strength, yield strength, and three-point bending strength is $9 \%, 14.68 \%$, and $6.26 \%$, respectively.

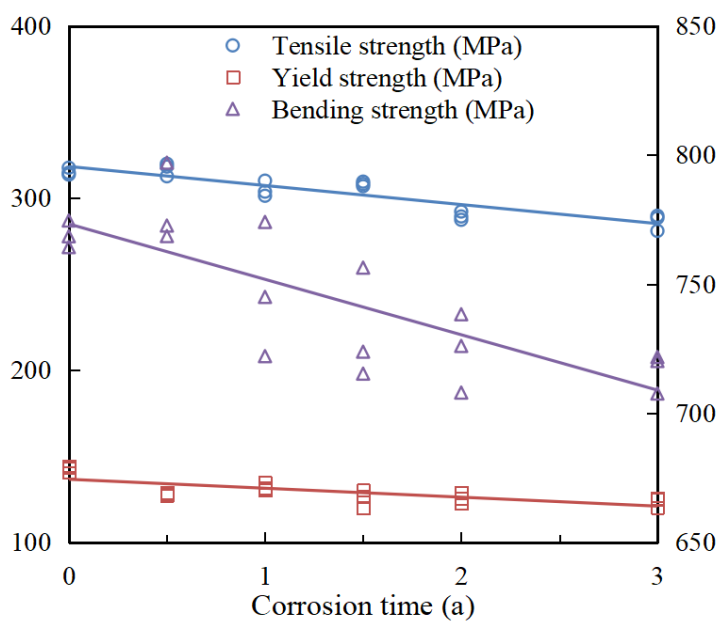

Figure 5. Change of tensile, yield, and bending strength over time. 


\subsection{Laboratory Test Result}

\subsubsection{Corrosion Process}

Figure 6 shows the morphology by SEM of the B10 copper specimen surface after the corrosion product is removed at different corrosion times in seawater. It is seen that small and shallow corrosion pits gradually appear on the surface as corrosion reaction proceeds. After 8 weeks, obvious spots are formed on the surface. EDS tests are carried out to determine the contents of $\mathrm{Cu}, \mathrm{Ni}$, and $\mathrm{O}$ on the cleaned surface after different corrosion times. It is seen that the content of $\mathrm{Ni}$ decreases gradually with the extension of corrosion time (Table 3). After 8 weeks, the ratio of $\mathrm{Cu}$ and $\mathrm{Ni}$ changed from close to 90/10 to $81.34 / 4.86$. It is inferred that $\mathrm{Ni}$ is removed from the metal surface in the dealloying corrosion process.
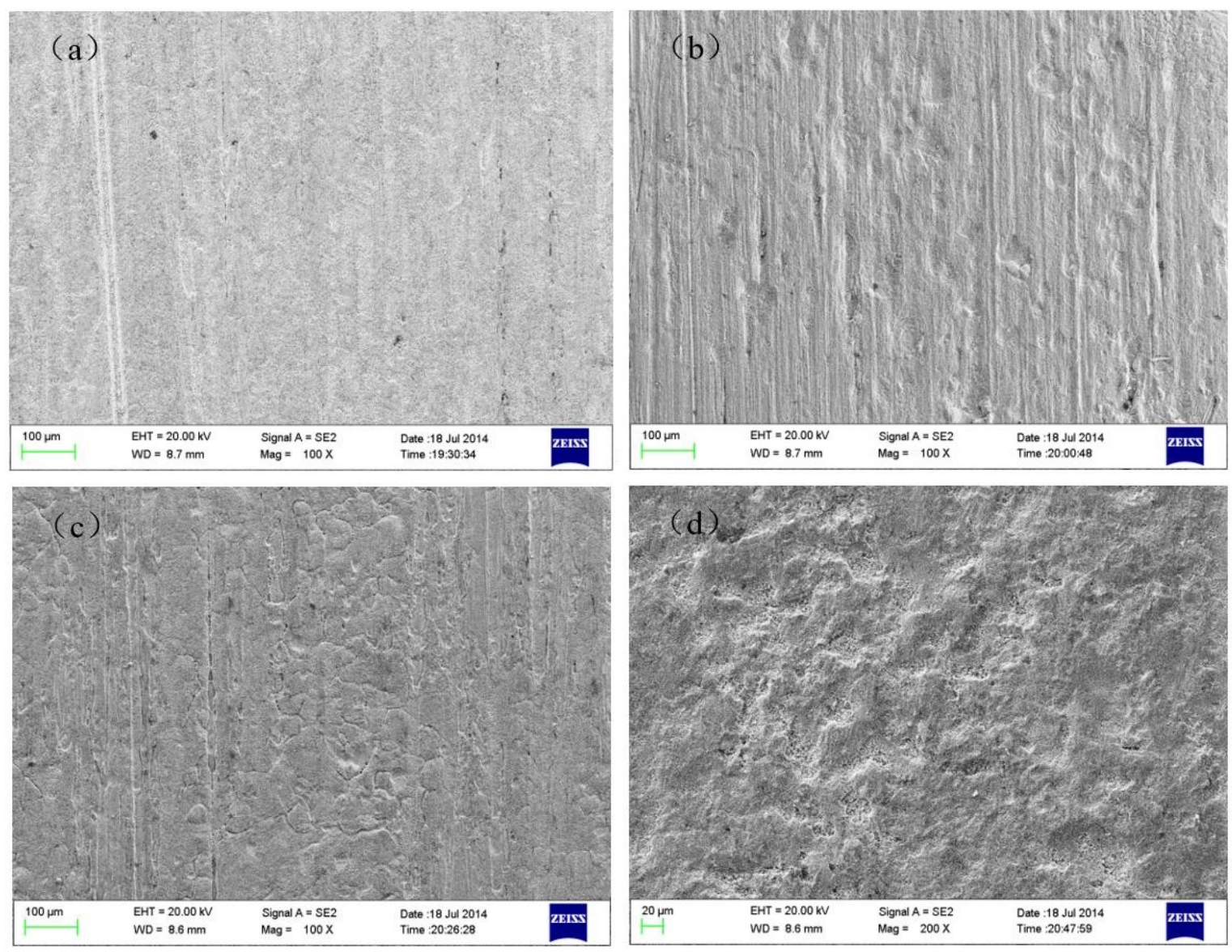

Figure 6. Morphology of the cleaned surface by SEM, (a) 1 week; (b) 2 weeks; (c) 4 weeks; (d) 8 weeks.

Table 3. Contents of element $\mathrm{Cu}, \mathrm{Ni}$, and $\mathrm{O}$ of the cleaned surface by EDS (wt\%).

\begin{tabular}{ccccc}
\hline Element & 1 Week & 2 Weeks & 4 Weeks & 8 Weeks \\
\hline $\mathrm{Cu}$ & 82.63 & 84.45 & 79.87 & 81.34 \\
$\mathrm{Ni}$ & 9.86 & 8.66 & 5.91 & 4.86 \\
$\mathrm{O}$ & 7.51 & 6.89 & 14.22 & 13.80 \\
\hline
\end{tabular}

A detailed SEM observation of the morphology of the dealloying corrosion zone of the specimens is shown in Figure 7 Dealloying is found in pitting areas, especially in seriously corroded areas. The dealloying corrosion reaction occurs along the grain boundary and fine particles regenerate and grow gradually along with time. EDS test was carried out on the regenerated particles on the specimen surface after 8 weeks of corrosion. It is seen 
from Table 4 that the regenerated particles are basically pure $\mathrm{Cu}$. According to the SEM morphology and EDS test analysis, the dealloying process of B10 copper alloy is basically the re-precipitation of alloy elements. At first, various elements are dissolved into the solution. Then the metal ions in the solution absorb the electrons left by the anode reaction and re-precipitate on the corroded surface, forming the porous particles.
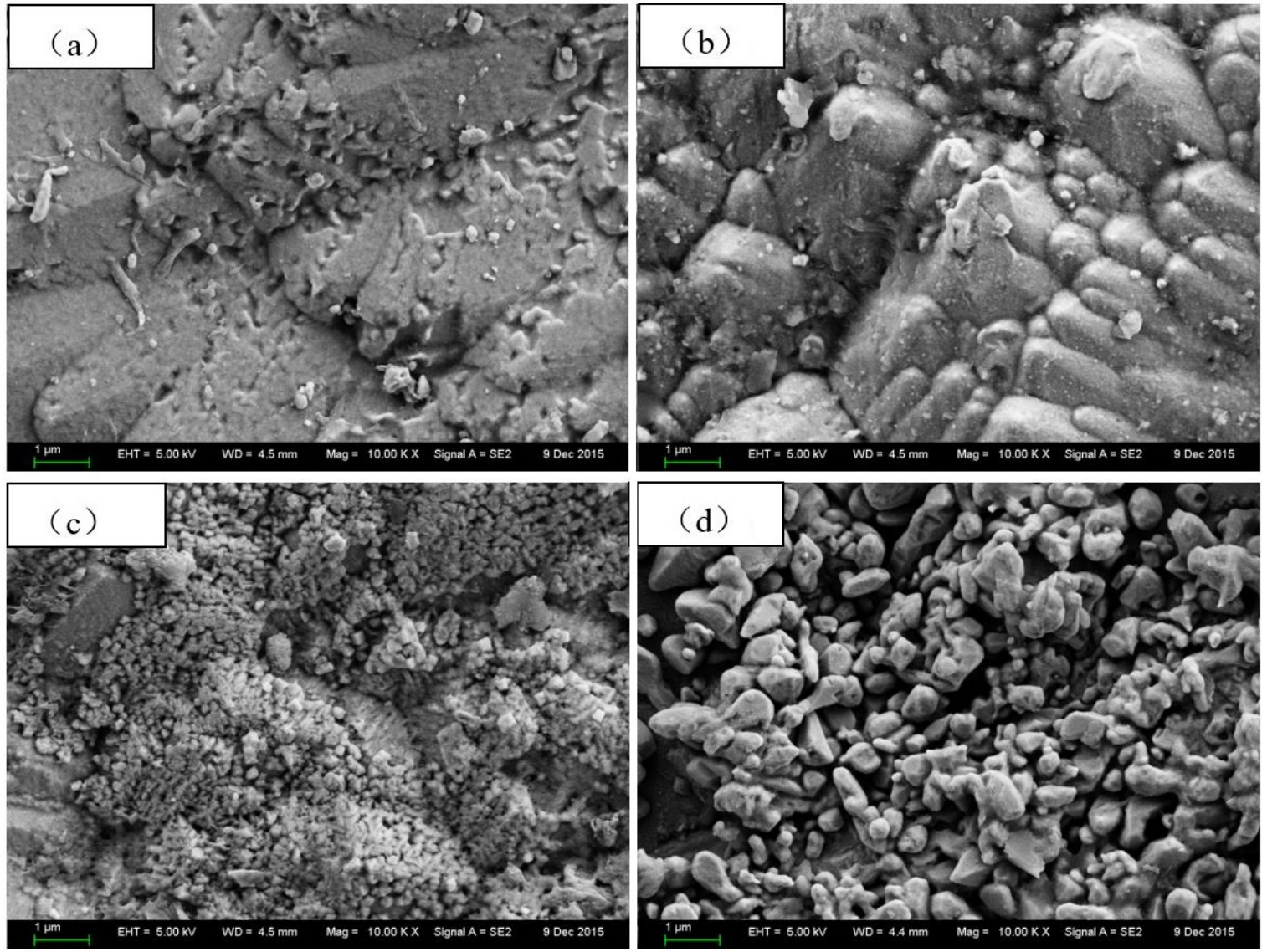

Figure 7. Morphology of the dealloying zone by SEM, (a) 1 week; (b) 2 weeks; (c) 4 weeks; (d) 8 weeks.

Table 4. Contents of different element of the re-precipitated particles by EDS (wt $\%$ ).

\begin{tabular}{cccccc}
\hline Element & Si & Mn & Fe & Ni & Cu \\
\hline Content $(w t \%)$ & 1.21 & 0.45 & 0.51 & 1.51 & 96.32 \\
\hline
\end{tabular}

EDS test was carried out to determine the content of different elements of the surface film. The results in Table 5 indicate that the elements in the film are mainly $\mathrm{Cu}$ and Ni, while $\mathrm{O}$ also makes up a considerable proportion. The content of $\mathrm{O}$ gradually increases with the continuous progress of the corrosion reaction, indicating that the oxidation reaction on the specimen surface continues to proceed with time.

Table 5. Contents of different elements of the surface film by EDS (wt $\%)$.

\begin{tabular}{ccccc}
\hline Element & $\mathbf{2} \mathbf{h}$ & $\mathbf{8} \mathbf{h}$ & $\mathbf{7 2} \mathbf{h}$ & $\mathbf{1 6 8} \mathbf{h}$ \\
\hline $\mathrm{Cu}$ & 79.93 & 72.56 & 67.19 & 59.71 \\
$\mathrm{Ni}$ & 10.4 & 9.2 & 8.63 & 2.47 \\
$\mathrm{O}$ & 9.55 & 18.24 & 22.95 & 27.8 \\
$\mathrm{Cl}$ & 0.12 & 0 & 1.23 & 10.02 \\
\hline
\end{tabular}




\subsubsection{Mass and Mechanical Property Loss}

Figure 8 shows the relationship between corrosion rate (average value of three specimens) and test time of the laboratory accelerated corrosion test. It is seen that corrosion rate under different test conditions vary greatly during the entire test period, indicating that environmental factors have great impacts on the corrosion process of B10 copper alloy although the surface film is formed and can partly hinder the process. The result shows great goodness-of-fitting to equation $C R=a . t^{n}$, with correlation coefficients higher than 0.9 for all the results as shown in Table 6. From the embedded subplot it is seen that among all the laboratory conditions, experiment G2 has the most significant accelerating effect for the long-term corrosion process. The corrosion process reaches the steady state after 4.25 years of test under laboratory conditions.

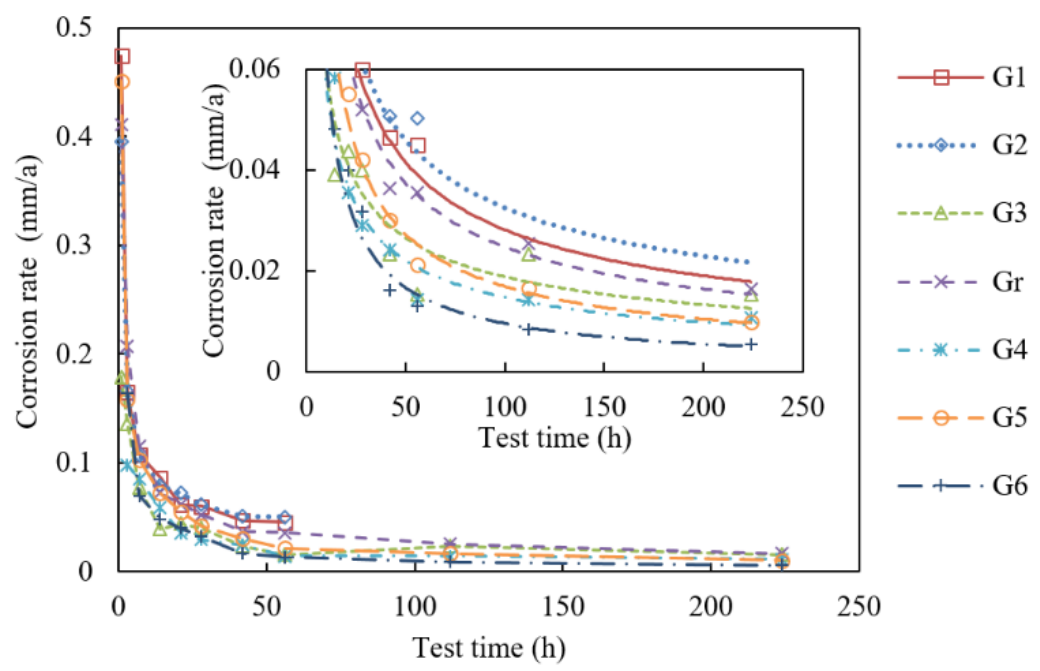

Figure 8. The relationship between corrosion rate and time in laboratory accelerated corrosion test.

Table 6. The fitting equations between corrosion rate and test time for laboratory accelerated corrosion results.

\begin{tabular}{ccc}
\hline No. & Fitting Equation & $\boldsymbol{R}^{\mathbf{2}}$ \\
\hline G1 & $C R=0.375 t^{-0.562}$ & 0.966 \\
G2 & $C R=0.326 t^{-0.501}$ & 0.970 \\
G3 & $C R=0.184 t^{-0.497}$ & 0.917 \\
Gr & $C R=0.380 t^{-0.593}$ & 0.994 \\
G4 & $C R=0.215 t^{-0.582}$ & 0.944 \\
G5 & $C R=0.406 t^{-0.691}$ & 0.991 \\
G6 & $C R=0.383 t^{-0.801}$ & 0.984 \\
\hline
\end{tabular}

Figure 9 shows the change of tensile strength, yield strength, and bending strength along with time for the six experiments, and the strength loss rate after 32 weeks (224 days) is listed in Table 7. It is seen that during the test period, tensile strength and yield strength do not show a monotonous decrease trend for all six experiments. This is possibly caused by the scatter between specimens and the influence of corrosion products.

After 32 weeks, for tensile strength, the maximum strength loss is less than $5 \%$, while in some experiments the strength has increased (G3). Yield strength also exhibits different trends in each experiment, with a strength loss rate ranging from $-7.8 \%$ to $-18.4 \%$. Bending strength shows a continuous decrease trend during the test period, and the loss range is between $10.4 \%$ and $12.5 \%$ for different experiments. 

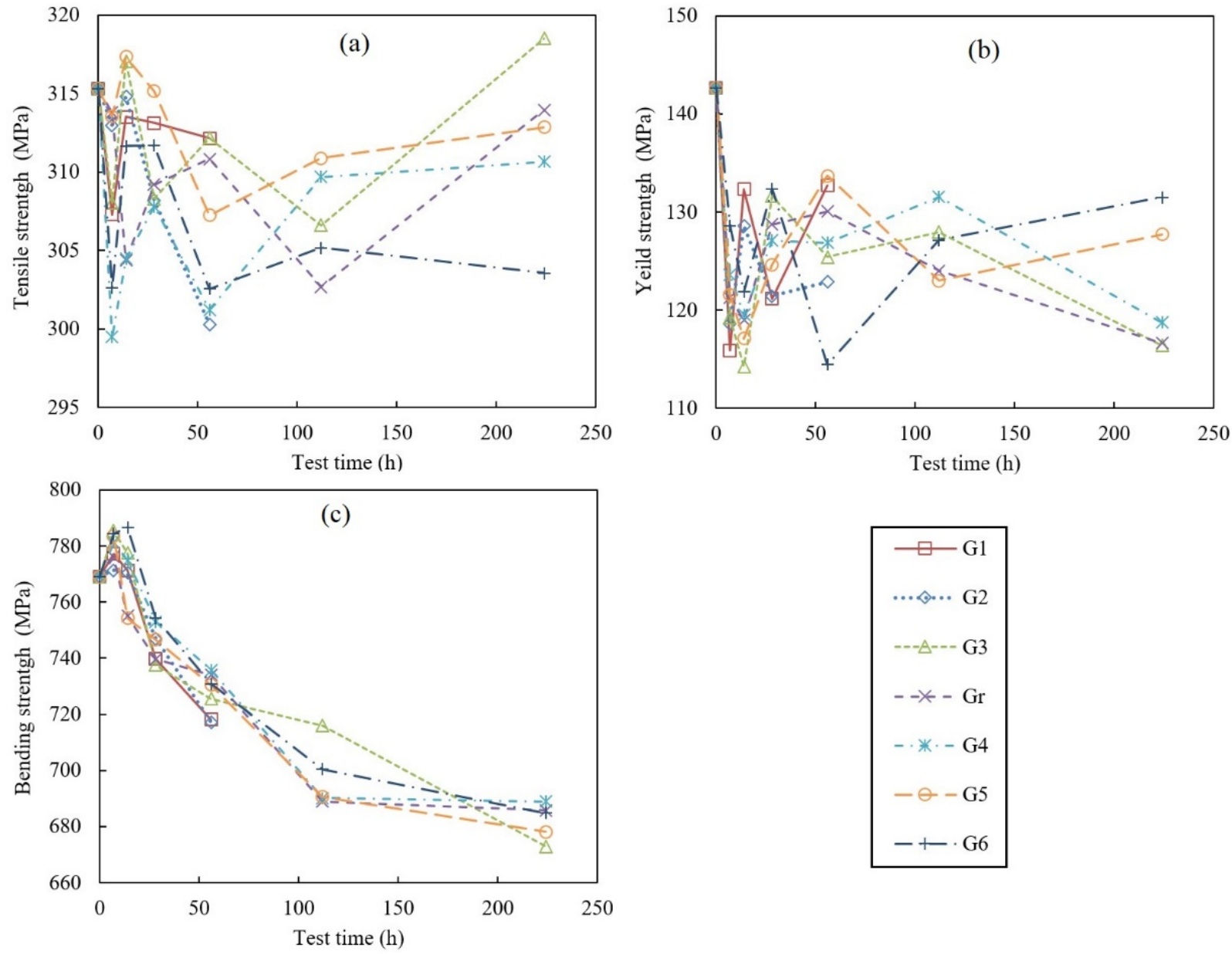

$$
\begin{aligned}
& -\square-\mathrm{G} 1 \\
& \cdots \odot \cdot \mathrm{G} 2 \\
& -----\mathrm{G} 3 \\
& --\star-\mathrm{Gr} \\
& -\cdots \cdot-\mathrm{G} 4 \\
& -\ominus-\mathrm{G} 5 \\
& -+-\mathrm{G} 6
\end{aligned}
$$

Figure 9. The relationship between mechanical properties and test time in laboratory accelerated conditions: (a) tensile strength; (b) yield strength; (c) bending strength.

Table 7. Loss of strength in laboratory accelerated corrosion test after 32 weeks.

\begin{tabular}{cccccccc}
\hline Experiment No. & G1 & G2 & G3 & Gr & G4 & G5 & G6 \\
\hline Tensile strength & - & - & $1.0 \%$ & $-0.4 \%$ & $-1.5 \%$ & $-0.8 \%$ & $-3.7 \%$ \\
Yield strength & - & - & $-18.4 \%$ & $-18.2 \%$ & $-16.8 \%$ & $-10.5 \%$ & $-7.8 \%$ \\
Bending strength & - & - & $-12.5 \%$ & $-10.8 \%$ & $-10.4 \%$ & $-11.8 \%$ & $-11.0 \%$ \\
\hline
\end{tabular}

\subsection{Acceleration Effect of Laboratory Corrosion Test}

\subsubsection{Acceleration Effect of $\mathrm{H}_{2} \mathrm{O}_{2}$}

In natural seawater, the corrosion process of B10 alloys is mainly controlled by the diffusion process of dissolved oxygen. The cathodic reaction $\mathrm{O}_{2}+2 \mathrm{H}^{+}+4 \mathrm{e} \rightarrow 2 \mathrm{OH}^{-}$ is actually a two-step process: $\mathrm{O}_{2}+2 \mathrm{H}^{+}+2 \mathrm{e} \rightarrow \mathrm{H}_{2} \mathrm{O}_{2}$, and $\mathrm{H}_{2} \mathrm{O}_{2}+2 \mathrm{e} \rightarrow 2 \mathrm{OH}^{-}$. When $\mathrm{H}_{2} \mathrm{O}_{2}$ is added, $\mathrm{H}_{2} \mathrm{O}_{2}$ acts as the cathodic depolarizer in the accelerated test. The corrosion process is accelerated at the second step. Figure 10 shows the polarization curve of the corrosion process in natural seawater and in the accelerated test. It is seen that the corrosion mechanism is the same as in natural seawater. 


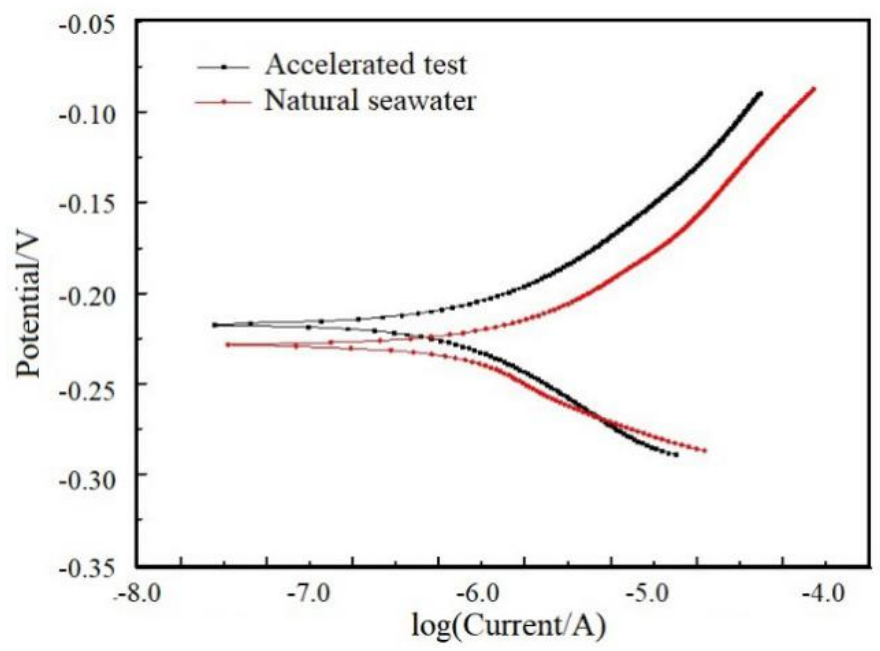

Figure 10. The polarization curve in natural seawater and in laboratory accelerated test.

The self-corrosion current density increases and the corrosion potential also moves towards the positive when $\mathrm{H}_{2} \mathrm{O}_{2}$ is added than in the natural seawater, indicating a significant acceleration effect of $\mathrm{H}_{2} \mathrm{O}_{2}$ the corrosion of $\mathrm{B} 10$ copper in seawater. Figure 11 shows the corrosion weight loss as a function of test time with and without $0.05 \mathrm{~mol} / \mathrm{L}$ $\mathrm{H}_{2} \mathrm{O}_{2}$ at $25{ }^{\circ} \mathrm{C}$ and $3.0 \%$ salinity. The results indicate that $\mathrm{H}_{2} \mathrm{O}_{2}$ can significantly accelerate the corrosion process of B10 alloy.

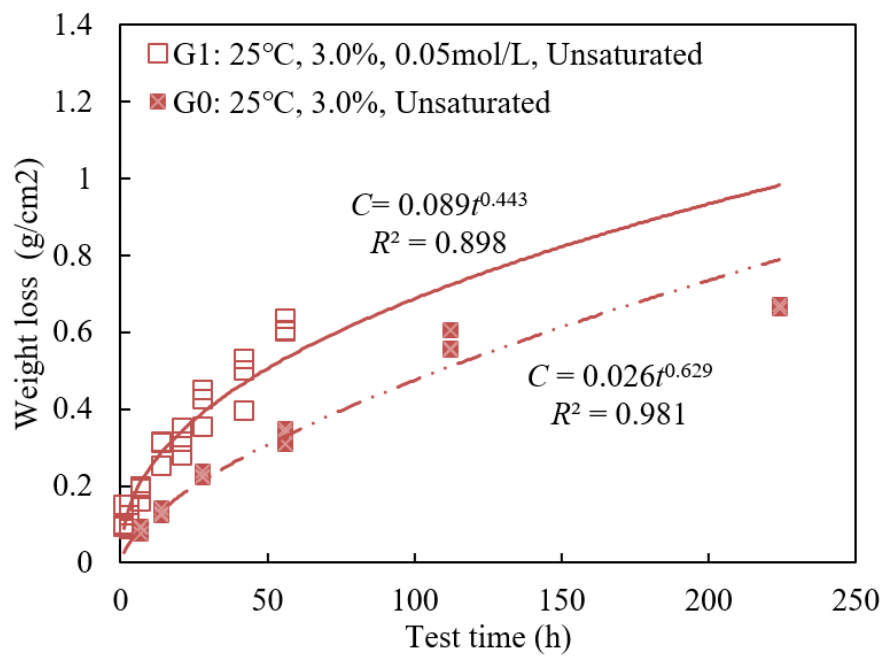

Figure 11. Metal weight loss as a function of test time with and without $\mathrm{H}_{2} \mathrm{O}_{2}$.

\subsubsection{Influence of Environmental Factors}

- Influence of dissolved oxygen

Dissolved oxygen (DO) is proven to be a fundamental factor that controls the corrosion process in seawater as it acts as the reactant [27]. For most metals, no undue corrosion attack is observed under high-purity water and steam conditions at room temperature due to the absence of DO [1]. DO removes hydrogen from the cathode and accelerates the corrosion reaction as a cathodic depolarizer and participates directly in the electrochemical processes as an oxidizer. Figure 12a shows that the corrosion rate is significantly higher when DO in seawater is saturated than unsaturated situations. This conclusion coincides with what has been reported in literatures that a higher DO concentration accelerates the corrosion process. It has been demonstrated that there is a good correlation between dissolved oxygen concentration and corrosion mass loss $[1,5,28]$. The relationship between 
corrosion rate and dissolved oxygen can be described with a linear $[2,29,30]$ or power-law equation [1].

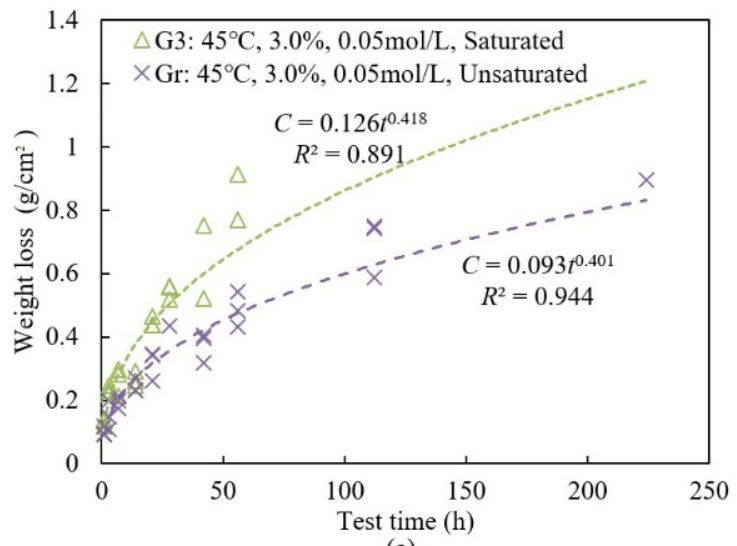

(a)

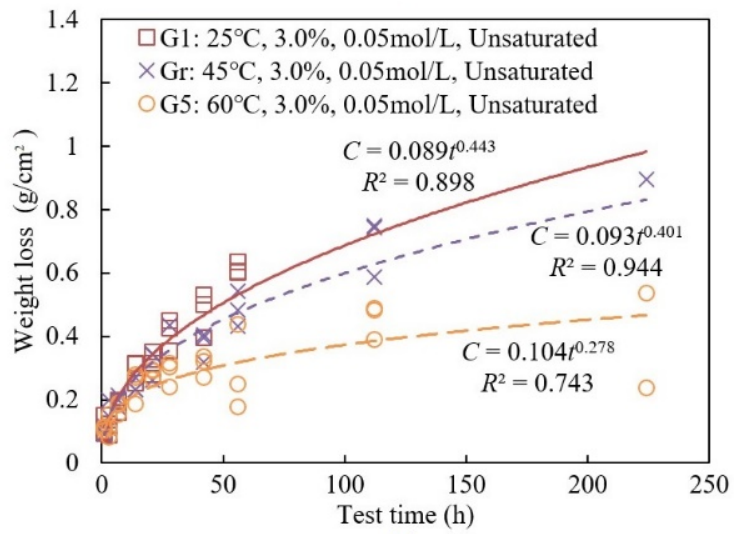

(c)

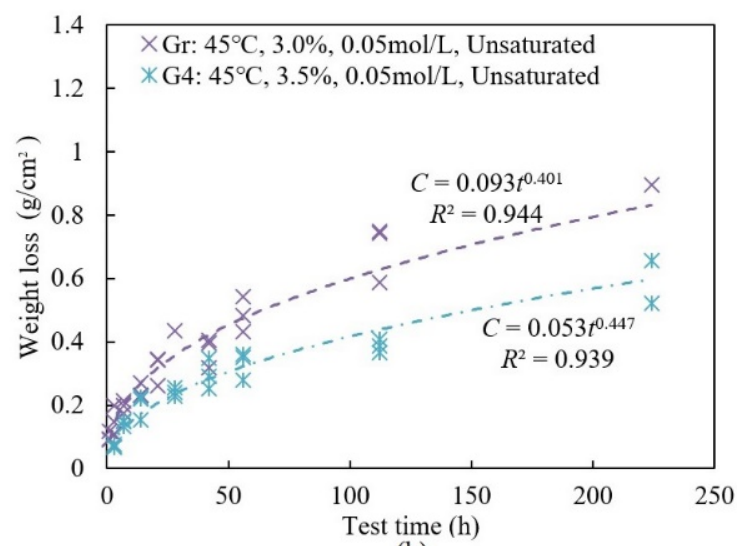

(b)

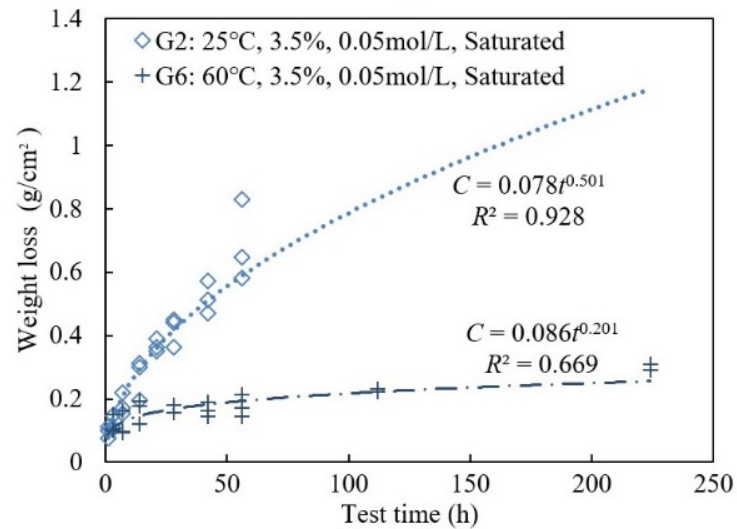

(d)

Figure 12. Metal weight loss as a function of test time in seawater under different test conditions: (a) saturated and unsaturated dissolved oxygen; (b) different salinity; (c) and (d) different temperature.

\section{- Influence of Salinity}

Salinity is also an important factor that can impact seawater conductivity and dissolved oxygen content at the same time. Figure $12 \mathrm{~b}$ indicates that increased salinity (from $3.0 \%$ to $3.5 \%$ ) results in the decrease of the corrosion rate. This is mainly caused by the escape of oxygen from seawater when salinity is increased. The solubility of oxygen in seawater is inversely related to salinity and temperature, following a polynomial equation [31,32]. The actual effect of salinity is the competitive effect of its positive impact on conductivity and negative impact on DO solubility [27]. Generally, when salinity is less than $3.0 \%[33,34]$, the increase of salinity accelerates the corrosion process mainly due to the increase of conductivity. When salinity is higher than $3.0 \%$, the escape of oxygen becomes the primary factor and the corrosion rate decreases [35]. Soares et al. [34] employed a truncated log-normal density function to describe the two-phase effect of salinity on corrosion rate in the open sea environment. As the salinity of natural seawater worldwide varies between $3.2 \%$ and $3.8 \%[2,29,36]$, a linear relation is also efficient to capture its effect on corrosion rate.

- Influence of temperature

The influence of temperature exists in two opposite effects in the actual open sea environment. On one hand, the increase of temperature accelerates the corrosion process due to increased oxygen diffusion rate and reaction activation energy. There have been studies indicating an approximately linear relation between temperature and corrosion 
rate [2,37]. On the other hand, oxygen solubility decreases as temperature increases [1,5], which follows a polynomial relation [31,32]. It is proven that in natural seawater DO varies with temperature from about $8.0 \mathrm{~mL} . \mathrm{L}^{-1}$ for surface waters in the arctic to around $4.5 \mathrm{~mL} . \mathrm{L}^{-1}$ in the tropics [36]. The total effect is the combination of the two conflicting tendencies in the actual environment. The result in Figure 12c, d shows that corrosion rate decreases when temperature increases from $25^{\circ} \mathrm{C}$ to $60^{\circ} \mathrm{C}$. This is mainly caused by the decreased oxygen solubility in seawater. According to the polynomial equation [31,32], DO content in seawater will decrease by approximately $39 \%$ when temperature increases from $25^{\circ} \mathrm{C}$ to $60{ }^{\circ} \mathrm{C}$

\subsubsection{Acceleration Effect of Designed Experiments}

Table 8 shows the average corrosion rate of three specimens after different test times. To analyze the sensitivity of corrosion rate to different environmental factors, the test conditions are marked as levels 1-3 and listed in Table 9 Then the sensitivity index of each environmental factor is calculated through the following two steps: (i) Calculate the average value $\bar{y}_{i}$ of each level by $\bar{y}_{i}=\frac{1}{m} \sum_{j=1}^{m} y_{i j}$, where $i=(1, \cdots, n)$ is the number of levels and $j$ is the number of samples in each level. For temperature, salinity, and dissolved oxygen, the values of $n$ are 3,2, and 2, while the values of $m$ are 2,3, and 3; (ii) Calculate the difference between $\bar{y}_{i}$ by $r=\max \left(\bar{y}_{1}, \cdots, \bar{y}_{n}\right)-\min \left(\bar{y}_{1}, \cdots, \bar{y}_{n}\right)$, then rank the value of $r$, which is also the rank of corresponding factors' sensitivity.

Table 8. The corrosion rate (average value of three parallel specimens) after different test times.

\begin{tabular}{|c|c|c|c|c|c|c|c|c|}
\hline \multirow{2}{*}{ No. } & \multicolumn{3}{|c|}{ Environmental Factor } & \multicolumn{5}{|c|}{ Corrosion Rate (mm/a) } \\
\hline & Temperature & Salinity & Dissolved Oxygen & 1 Week & 2 Weeks & 4 Weeks & 6 Weeks & 8 Weeks \\
\hline G1 & $1\left(25^{\circ} \mathrm{C}\right)$ & $1(3.0)$ & 2 (Unsaturated) & 0.108 & 0.086 & 0.060 & 0.046 & 0.045 \\
\hline G2 & $1\left(25^{\circ} \mathrm{C}\right)$ & $2(3.5)$ & 1 (Saturated) & 0.107 & 0.079 & 0.061 & 0.051 & 0.050 \\
\hline G3 & $2\left(45^{\circ} \mathrm{C}\right)$ & $1(3.0)$ & 1 (Saturated) & 0.136 & 0.077 & 0.039 & 0.044 & 0.040 \\
\hline G4 & $2\left(45^{\circ} \mathrm{C}\right)$ & $2(3.5)$ & 2 (Unsaturated) & 0.085 & 0.058 & 0.035 & 0.029 & 0.024 \\
\hline G5 & $3\left(60^{\circ} \mathrm{C}\right)$ & $1(3.0)$ & 2 (Unsaturated) & 0.103 & 0.072 & 0.042 & 0.030 & 0.021 \\
\hline G6 & $3\left(60^{\circ} \mathrm{C}\right)$ & $2(3.5)$ & 1 (Saturated) & 0.070 & 0.048 & 0.032 & 0.016 & 0.013 \\
\hline
\end{tabular}

Table 9. Sensitivity of corrosion rate to environmental factors after different test times.

\begin{tabular}{cccccc}
\hline \multirow{2}{*}{ Environmental Factor } & \multicolumn{5}{c}{ Test Time } \\
\cline { 2 - 6 } & $\mathbf{1}$ Week & 2 Weeks & $\mathbf{4}$ Weeks & $\mathbf{6}$ Weeks & $\mathbf{8 ~ W e e k s}$ \\
\hline Temperature & Last & Primary & Primary & Primary & Primary \\
Salinity & Primary & Last & Last & Last & Last \\
Dissolved oxygen & Secondary & Secondary & Secondary & Secondary & Secondary \\
\hline
\end{tabular}

Take the 1-week test results as an example; the values $\bar{y}_{T i}$ of temperature are $\bar{y}_{T 1}=\frac{1}{2}(0.108+0.107)=0.107, \bar{y}_{T 2}=\frac{1}{2}(0.136+0.085)=0.110, \bar{y}_{T 3}=\frac{1}{2}(0.103+0.070)=$ 0.086 and the difference $r_{T}=0.110-0.0086=0.024$. With the same procedure, the $r$ values of salinity and dissolved oxygen $\left(r_{S}\right.$ and $\left.r_{D O}\right)$ are calculated and they are 0.028 and 0.006 , respectively. As $r_{S}>r_{T}>r_{D O}$, it is indicated that salinity is the primary factor, temperature is secondary, and dissolved oxygen is the last.

The sensitivity of corrosion rate to environmental factors is listed in Table 9. It is seen that short-term and long-term corrosion processes exhibit different sensitivity to each factor. At the initial stage, salinity acts as the primary factor. After 2 weeks, temperature becomes primary while salinity is last.

From Figure 8 and Table 8, we can see that experiment G2 has the most significant accelerating effect for long-term corrosion among all the designed experiments. For G2, the temperature is $25{ }^{\circ} \mathrm{C}$, salinity is $3.5 \%$, and dissolved oxygen is saturated. As has been discussed in the previous section, higher salinity leads to the escape of oxygen from 
seawater and slows down the corrosion process. In view of this, there will be better accelerating effect if salinity is decreased and kept at 3.0\% in this series of tests.

The results of outdoor exposure and experiment G2 were fit to the power relation $C=C_{1} \cdot t^{n}$, and the parameters are listed in Table 10. According to Morcillo's principle [25], the corrosion process reaches the steady state when the decrease of the corrosion rate in one year is less than $10 \%$, and the change in the corrosion rate in a year at the steady state is less than $10 \%$. Based on this, Cai et al. [26] proposed the equation for the calculation of stabilization time $t_{s}$ and the stationary corrosion rate $\alpha$, which are

$$
\begin{gathered}
t_{s}=\frac{1}{0.9^{1 /(n-1)}-1}, \\
\alpha=C_{1} \cdot n \cdot t_{s}^{n-1}
\end{gathered}
$$

Table 10. Fitting parameters in corrosion kinetic models for mass loss results of outdoor exposure and experiment G2.

\begin{tabular}{cccccc}
\hline & $\boldsymbol{C}_{1}$ & $\boldsymbol{n}$ & $\boldsymbol{t}_{\boldsymbol{s}}$ (years) & $\boldsymbol{\alpha}\left({\left.\mathrm{g} . \mathrm{cm}^{-2} \cdot \text { year }^{-1}\right)}\right.$ & Acceleration Ratio \\
\hline Outdoor & 1.72 & 0.426 & 4.96 & 0.292 & - \\
G2 & 1.50 & 0.501 & 4.25 & 0.365 & 1.25 \\
\hline
\end{tabular}

As shown in Table 10, the stationary corrosion rate $\alpha$ of outdoor exposure and experiment G2 are 0.292 and 0.365 g.cm ${ }^{-2}$.year ${ }^{-1}$, respectively. The acceleration ratio is $0.365 / 0.292=1.25$, which indicates that the corrosion process is accelerated by 1.25 times.

\section{Discussion}

This paper tries to explore the possibility of simulating the outdoor corrosion process under laboratory conditions within a shorter period of test time. To achieve this, there are mainly two aspects that should be guaranteed. The first is corrosion mechanism consistency which means outdoor and laboratory tests follow the same corrosion process. This can be proved by the morphology and composition of corrosion products, as well as corrosion kinetics and mechanical property degradation path. The second is that there should be a significant acceleration effect which can be described quantitatively. This is based on the quantitative design of all the influential environmental factors and calibration of the acceleration models.

In this paper, evidences from both morphology and mechanical properties have indicated similarity and consistency between outdoor and laboratory corrosion test results. In summary, the major corrosion product is $\mathrm{Cu}_{2} \mathrm{O}$ in both outdoor and laboratory tests and it exhibits a good inhibitive effect to the corrosion process as it is compactly attached to the metal surface. The overall trends of corrosion kinetics are consistent, in which corrosion rate is relatively high at first and then decreases. Experiment results show high goodness-of-fitting to equation $C=A . t^{n}$ with correlation coefficients higher than 0.9 for most cases. Pits of different sizes are observed on the cleaned metal surface because of localized corrosion and recrystallized metal particles are found on the metal surface due to the dealloying process.

However, there also exist some differences between outdoor and laboratory conditions and test results. For example, the exponent $n$, which is an indicator of the protective ability of corrosion products to the corrosive environment, varies between outdoor and laboratory tests. Specifically, the value of $n$ varies from 0.201 to 0.629 in accelerated corrosion tests, indicating that the long-term corrosion kinetics of each test are different. In this paper, experiment G2 is chosen as the best accelerated corrosion test because of its significant acceleration effect. However, exponent $n$ for G2 and the outdoor exposure test are 0.501 and 0.426 , respectively. It is seen that differences exist in the long-term corrosion kinetics, although the fundamental corrosion process is the same. Mechanical properties, including 
tensile strength, yield strength, and bending strength, exhibit an overall decrease trend in different degrees. The degradation process in the outdoor environment is monotonous while in laboratory conditions it is fluctuated. This is possibly caused by the scatter of specimens. The relations between outdoor and laboratory conditions are difficult to be extracted from these results.

Moreover, experiment G2 has an accelerated ratio of 1.25 compared to the outdoor environment. It is obvious that the acceleration effect is unable to shorten the test time remarkably. As discussed above, there are better accelerating conditions that can be more representative of the outdoor environment and produce a better acceleration effect. The conditions can be determined by the combination of a quantitative design-of-experiment (DOE) methodology and parameter optimization of the acceleration model. In view of this, additional work is needed to move the current qualitative method forward to quantitative models.

There exist multiple limitations in conventional experiment techniques, parameter measurement, as well as model establishment. One major problem is that the scatter of corrosion loss measurement is unavoidable due to the randomness induced by multiple sources, including specimen, test conditions, measurement procedure, and more undetectable sources. In this paper, it is seen that the relative difference of corrosion loss between the parallel specimens can be as high as 148\% (experiment G5 at 56 weeks). Fluctuation of property degradation path may also be a common phenomenon and causes poor goodnessof-fitting to corrosion kinetic models especially when there are no parallel specimens.

In addition, conventional experiments usually take years, even decades, while the size of samples is small. Take the outdoor experiment in this paper as an example, only four groups of samples (three parallel specimens in each group) are obtained in a 3-year experiment. Thus, the development of equivalent accelerated corrosion test techniques under laboratory conditions is of great value. This paper has made some attempts to explore this topic, but there is still a distance to make it applicable in corrosion engineering practice. When considering the multi-phases characteristic of the corrosion process and the influence of biological activity in the actual marine environment, this topic will inevitably be much more challenging.

In view of this, new experimental techniques are needed to avoid the above-mentioned shortcomings of conventional methods. In recent years, corrosion monitoring techniques have been widely applied in corrosion science and engineering [38,39]. By measuring electrochemical signals with sensors under different test conditions, it is able to obtain a large amount of valuable data. With the help of acceleration models and sensitivity analysis, it is convenient to distinguish important influential factors among all the environmental factors and get a quantitative insight into the effect of each factor. Furthermore, it is also able to extrapolate the experiment results to different environments when the environment is accurately described. It would be a basic requirement that both outdoor and laboratory experiments should be conducted considering the essential difference between them. A systematic framework, including the design of experiment, as well as acceleration model construction and calibration, is needed. This will be further studied in future works.

\section{Conclusions}

This paper designed and conducted outdoor exposure and laboratory accelerated corrosion tests on B10 copper alloy. The orthogonal design methodology is a promising tool to explore the quantitative law of both individual and net effects of different environmental factors. The comprehensive effect of test conditions is strongly related to the content of dissolved oxygen. When temperature or salinity increases, the corrosion rate decreases due to the escape of oxygen from seawater. The overall effect of temperature and salinity is the combination of their positive effect on corrosion rate directly and negative effect on dissolved oxygen content. Both outdoor exposure and laboratory experiments are able to provide convincing clues which guarantee the same corrosion mechanism. Corrosion products and morphology, corrosion kinetics, and mechanical properties show good agreement 
between outdoor and laboratory results. $\mathrm{H}_{2} \mathrm{O}_{2}$ can significantly accelerate the corrosion process of B10 copper alloy. Among all the designed laboratory experiments, G2 has the most significant acceleration effect with an acceleration ratio of 1.25. It is expected that, with the help of more quantitatively designed experiments and models, better acceleration conditions can be obtained which are able to simulate the actual corrosion process with a shorter test time.

Author Contributions: Conceptualization, Y.C. and X.M.; methodology, Y.C., Y.X. and W.Z.; software, Y.C.; validation, J.Y., Y.Z. and Y.X.; formal analysis, Y.C., M.W. and W.Z.; investigation, Y.C.; resources, Y.Z. and J.Y.; data curation, J.Y., M.W. and Y.C.; writing-original draft preparation, Y.C.; writingreview and editing, Y.X., W.Z. and X.M.; visualization, Y.C.; supervision, Y.Z. and X.M.; project administration, Y.Z., M.W., K.Z. and X.M.; funding acquisition, Y.Z. and X.M. All authors have read and agreed to the published version of the manuscript.

Funding: This research was funded by National Natural Science Foundation of China, grant number 52075020 and Southwest Institute of Technology and Engineering Cooperation Fund, grant number WZDW592019080301.

Institutional Review Board Statement: Not applicable.

Informed Consent Statement: Not applicable.

Data Availability Statement: The processed data are available from the corresponding author upon reasonable request.

Conflicts of Interest: The authors declare no conflict of interest.

\section{References}

1. Roberge, P.R. Corrosion Engineering: Principles and Practice; McGraw-Hill: New York, NY, USA, 2008.

2. Guedes Soares, C.; Garbatov, Y.; Zayed, A. Effect of environmental factors on steel plate corrosion under marine immersion conditions. Corros. Eng. Sci. Technol. 2011, 46, 524-541. [CrossRef]

3. Gu, T.; Jia, R.; Unsal, T.; Xu, D. Toward a better understanding of microbiologically influenced corrosion caused by sulfate reducing bacteria. J. Mater. Sci. Technol. 2019, 35, 631-636. [CrossRef]

4. Jia, R.; Unsal, T.; Xu, D.; Lekbach, Y.; Gu, T. Microbiologically influenced corrosion and current mitigation strategies: A state of the art review. Int. Biodeterior. Biodegrad. 2019, 137, 42-58. [CrossRef]

5. Revie, R.W.; Uhlig, H.H. Corrosion and Corrosion Control, 4th ed.; John Wiley \& Sons: Hoboken, NJ, USA, 2008 ; p. 513.

6. Atashin, S.; Toloei, A.S.; Pakshir, M. Simultaneous Investigation of Marine Factors Effect on Corrosion Rate of SS 304 in Turbulent Condition. J. Mater. Eng. Perform. 2013, 22, 2038-2047. [CrossRef]

7. Toloei, A.; Atashin, S.; Pakshir, M. Corrosion rate of carbon steel under synergistic effect of seawater parameters including $\mathrm{pH}$, temperature, and salinity in turbulent condition. Corros. Rev. 2013, 31, 135-144. [CrossRef]

8. Melchers, R.E. Modeling of marine immersion corrosion for mild and low-alloy steels—Part 1: Phenomenological model. Corrosion 2003, 59, 319-334. [CrossRef]

9. Melchers, R.E. Long-term immersion corrosion of steels in seawaters with elevated nutrient concentration. Corros. Sci. 2014, 81, 110-116. [CrossRef]

10. Melchers, R.E.; Jeffrey, R.J. Long-Term Corrosion of Mild Steel in Natural and UV-Treated Coastal Seawater. Corrosion 2014, 70, 804-818. [CrossRef]

11. Kovalenko, R.; Melchers, R.E.; Chernov, B. Long-term immersion corrosion of steel subject to large annual variations in seawater temperature and nutrient concentration. Struct. Infrastruct. Eng. 2016, 13, 978-987. [CrossRef]

12. Zhao, Y.H.; Lin, L.Y.; Cui, D.W. Localized corrosion of copper alloys in China seawater for 16 years. Trans. Nonferrous Met. Soc. China 2004, 14, 1082-1090.

13. Cai, B.P.; Liu, Y.H.; Ren, C.K.; Liu, Z.K.; Tian, X.J.; Abulimiti, A.B.B. Experimental study of galvanic corrosion behaviour of carbon fibre composite coupled to aluminium in artificial seawater. Corros. Eng. Sci. Technol. 2013, 47, 289-296. [CrossRef]

14. Zhang, Y.; Yin, X.; Yan, F. Effect of halide concentration on tribocorrosion behaviour of 304SS in artificial seawater. Corros. Sci. 2015, 99, 272-280. [CrossRef]

15. Santos, C.I.S.; Mendonça, M.H.; Fonseca, I.T.E. Corrosion of brass in natural and artificial seawater. J. Appl. Electrochem. 2006, 36, 1353-1359. [CrossRef]

16. Chen, J.; Yan, F.-y. Tribocorrosion behaviors of Ti-6Al-4V and Monel K500 alloys sliding against 316 stainless steel in artificial seawater. Trans. Nonferrous Met. Soc. China 2012, 22, 1356-1365. [CrossRef]

17. Zhang, X.; Hoogeland, M. Influence of deformation on corrosion of mooring chain steel in seawater. Mater. Corros. 2019, 70, 962-972. [CrossRef]

18. Parvizi, M.; Aladjem, A.; Castle, J. Behaviour of 90-10 cupronickel in sea water. Int. Mater. Rev. 1988, 33, 169-200. [CrossRef] 
19. Melchers, R. Temperature effect on seawater immersion corrosion of 90: 10 copper-nickel alloy. Corrosion 2001, 57, 440-451. [CrossRef]

20. Chen, J.; Li, Z.; Zhu, A.; Luo, L.; Liang, J. Corrosion behavior of novel imitation-gold copper alloy with rare earth in $3.5 \% \mathrm{NaCl}$ solution. Mater. Des. 2012, 34, 618-623. [CrossRef]

21. Kear, G.; Barker, B.; Stokes, K.; Walsh, F. Electrochemical corrosion behaviour of 90-10 Cu-Ni alloy in chloride-based electrolytes J. Appl. Electrochem. 2004, 34, 659-669. [CrossRef]

22. Sanchez, M.; Gamby, J.; Perrot, H.; Rose, D.; Vivier, V. Microelectrochemistry of copper in NaCl solution: Comparison between conventional microelectrode and microelectrochemical cell. Electrochem. Commun. 2010, 12, 1230-1232. [CrossRef]

23. Gkatzogiannis, S.; Weinert, J.; Engelhardt, I.; Knoedel, P.; Ummenhofer, T. Correlation of laboratory and real marine corrosion for the investigation of corrosion fatigue behaviour of steel components. Int. J. Fatigue 2019, 126, 90-102. [CrossRef]

24. Ding, K.K.; Fan, L.; Yu, M.J.; Guo, W.M.; Hou, J.; Lin, C.G. Sea water corrosion behaviour of T2 and 12832 copper alloy materials in different sea areas. Corros. Eng. Sci. Technol. 2019, 54, 476-484. [CrossRef]

25. Morcillo, M.; Chico, B.; Diaz, I.; Cano, H.; de la Fuente, D. Atmospheric corrosion data of weathering steels-A review. Corros. Sci. 2013, 77, 6-24. [CrossRef]

26. Cai, Y.K.; Zhao, Y.; Ma, X.B.; Zhou, K.; Wang, H. Long-Term Prediction of Atmospheric Corrosion Loss in Various Field Environments. Corrosion 2018, 74, 669-682. [CrossRef]

27. Cai, Y.K.; Xu, Y.M.; Zhao, Y.; Ma, X.B.; Zhou, K. A spatial-temporal approach for corrosion prediction in time-varying marine environment. J. Loss Prev. Process. Ind. 2020, 66, 104161. [CrossRef]

28. Venkatesan, R.; Venkatasamy, M.A.; Bhaskaran, T.A.; Dwarakadasa, E.S.; Ravindran, M. Corrosion of ferrous alloys in deep sea environments. Br. Corros. J. 2003, 37, 257-266. [CrossRef]

29. Melchers, R.E. Probabilistic models for corrosion in structural reliability assessment-Part 2: Models based on mechanics. J. Offshore Mech. Arct. 2003, 125, 272-280. [CrossRef]

30. Melchers, R.E. Effect of immersion depth on marine corrosion of mild steel. Corrosion 2005, 61, 895-906. [CrossRef]

31. Ijsseling, F.P. General guidelines for corrosion testing of materials for marine applications: Literature review on sea water as test environment. Br. Corros. J. 1989, 24, 53-78. [CrossRef]

32. Roberge, P.R. Handbook of Corrosion Engineering; McGraw-Hill: New York, NY, USA, 2000.

33. Kirk, W.W.; Pikul, S.J. Seawater corrosivity around the world: Results from three years of testing. In Corrosion in Natural Waters; ASTM International: West Conshohocken, PA, USA, 1990.

34. Soares, C.G.; Garbatov, Y.; Zayed, A.; Wang, G. Non-linear Corrosion Model for Immersed Steel Plates Accounting for Environmental Factors. Trans. Soc. Nav. Archit. Mar. Eng. 2005, 113, 306-322.

35. Zakowski, K.; Narozny, M.; Szocinski, M.; Darowicki, K. Influence of water salinity on corrosion risk-the case of the southern Baltic Sea coast. Environ. Monit. Assess. 2014, 186, 4871-4879. [CrossRef] [PubMed]

36. Chandler, K.A. Marine and Offshore Corrosion; Elsevier Ltd., Butterworth-Heinemann: Oxford, UK, 1985.

37. Laque, F.L. Marine Corrosion: Causes and Prevention; Wiley-Inter Science: New York, NY, USA, 1975.

38. Xia, D.-H.; Song, S.-Z.; Behnamian, Y. Detection of corrosion degradation using electrochemical noise (EN): Review of signal processing methods for identifying corrosion forms. Corros. Eng. Sci. Technol. 2016, 51, 527-544. [CrossRef]

39. Ma, C.; Wang, Z.; Behnamian, Y.; Gao, Z.; Wu, Z.; Qin, Z.; Xia, D.-H. Measuring atmospheric corrosion with electrochemical noise: A review of contemporary methods. Measurement 2019, 138, 54-79. [CrossRef] 